only typical granular type of diphtheria bacilli being considered positive, proves absolutely that if we are to control epidemics of diphtheria by the isolation of carriers, nose cultures must always be taken with those from the throat.

The tables indicate the importance of taking cultures from both nose and throat in such investigations. It will be noticed that Investigations $E$ and $F$, in which cultures were taken only from the throat, the percentages of positives are markedly lower than those of the investigations in which cultures were obtained from both nose and throat. The importance of nose cultures is conclusively demonstrated in the percentage average of positives, as nose cultures gave 42.2, compared with the percentage average of throat cultures, 7.9.

Inasmuch as only 28 per cent. of all positive cultures in these investigations were from the throat, one can readily see how many positives, 72 per cent., would not have been detected if nose cultures were not taken.

\begin{tabular}{|c|c|c|c|c|c|c|c|}
\hline $\begin{array}{l}\text { Investi- } \\
\text { gation }\end{array}$ & Total & $\begin{array}{c}\text { Total } \\
\text { Positive }\end{array}$ & $\begin{array}{c}\text { Positive } \\
\text { Nose }\end{array}$ & $\begin{array}{l}\text { Positive } \\
\text { Throat }\end{array}$ & $\begin{array}{c}\text { Positive } \\
\text { Nose } \\
\text { and } \\
\text { Negative } \\
\text { Throat }\end{array}$ & $\begin{array}{c}\text { Negative } \\
\text { Nose } \\
\text { and } \\
\text { Positive } \\
\text { Throat }\end{array}$ & $\begin{array}{c}\text { Positive } \\
\text { Nose } \\
\text { and } \\
\text { Positive } \\
\text { Throat }\end{array}$ \\
\hline $\begin{array}{l}\mathbf{A} \\
\mathbf{B} \\
\mathbf{C} \\
\mathbf{D} \\
\mathbf{E} \\
\mathbf{F}\end{array}$ & $\begin{array}{r}132 \\
65 \\
17 \\
55 \\
101 \\
99\end{array}$ & $\begin{array}{r}28 \\
24 \\
15 \\
22 \\
6 \\
5\end{array}$ & $\begin{array}{l}25 \\
21 \\
14 \\
18\end{array}$ & $\begin{array}{r}10 \\
8 \\
1 \\
6 \\
6 \\
5\end{array}$ & $\begin{array}{l}18 \\
16 \\
14 \\
16 \\
\cdots \\
. .\end{array}$ & $\begin{array}{c}3 \\
3 \\
1 \\
4 \\
. \\
\because .\end{array}$ & $\begin{array}{l}7 \\
5 \\
0 \\
2 \\
. \\
\therefore\end{array}$ \\
\hline
\end{tabular}

TA\&LE 2.-TABLE OF PERCENTAGES OF INVESTIGATIONS IN TABLE 1 *

\begin{tabular}{|c|c|c|c|}
\hline Investigation & $\begin{array}{c}\text { Percentage } \\
\text { of } \\
\text { Positives }\end{array}$ & $\begin{array}{c}\text { Percentage } \\
\text { of } \\
\text { Positive } \\
\text { Throat }\end{array}$ & $\begin{array}{c}\text { Percentage } \\
\text { of } \\
\text { Positive } \\
\text { Nose }\end{array}$ \\
\hline 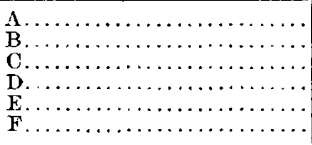 & $\begin{array}{r}21.2 \\
36.9 \\
88.2 \\
40.0 \\
5.9 \\
5.0\end{array}$ & $\begin{array}{r}7.6 \\
12.3 \\
5.8 \\
10.9 \\
5.9 \\
5.0\end{array}$ & $\begin{array}{l}18.9 \\
32.3 \\
82.3 \\
34.6 \\
\cdots . .\end{array}$ \\
\hline Average total percentages. . & 32.8 & 7.9 & 42,2 \\
\hline
\end{tabular}

* Of all positives, 87.6 per cent. were found in cultures from nose; 28 per cent, of all positives were found in cultures from throat.

Another interesting observation is the total percentage average of positives, 32.8 , the majority of which can be classed as diphtheria carriers. This large percentage is undoubtedly due to the fact that probably all the persons examined were recent contacts with diphtheria cases, as cases were present in the school examined.

THE USE OF THE SCHICK TEST IN DISTINGUISHING CONTACTS FROM CARRIERS

A point of great interest, in view of the rules of the California State Board of Health relative to contacts and carriers, was brought out in Group $C$ of the preceding investigation. This group was composed of young adult students in a large university. In order to distinguish between the contacts and carriers, without waiting for the elapsing of the incubation period, it was decided to make use of the Schick test. With this test it was proved in forty-eight hours that the whole group was immune. The members of the group were accordingly classed as carriers, and so relieved of some of the inconveniences attending the quarantine of contacts.
The results of the test were borne out by the fact that none of the carriers developed the disease. Another example of the value of the Schick test was shown in another investigation in which several carriers developed diphtheria, and in which the test was not used. Had the carriers in this group been given the Schick test as those in Group C, the nonimmunes would have been detected and could have been immunized before the development of the disease.

\section{CULTURAL EXPERIMENTS WITH THE SPIROCHAETA PALLIDA DERIVED FROM THE PARETIC BRAIN}

\author{
UDO J. WILE, A.B., M.D. \\ PAUL HENRY DE KRUIF, B.S. \\ ANN ARBOR, MICH.
}

Recently, ${ }^{1}$ one of us described the successful implantation of spirochetes and the transmission of experimental syphilis to rabbits from the living paretic brain.

At present this experimental syphilis has been transmitted to five generations of rabbits.

The initial inoculation of brain was made into the testis of a large rabbit, June 11, 1915, and thirty-two days later, July 11, large numbers of spirochetes were demonstrable in both testes by aspiration. August 12 , about two months after the initial inoculation, the right testis was castrated under aseptic precautions, one portion being used for implantation into other animals, and the remaining portion for cultural experiments.

After thorough maceration with normal saline, the material was planted deep into tubes of rabbit kidney ascitic agar mediums. The cultures were covered with paraffin oil and cultivated under anaerobic conditions. Six tubes were inoculated from this material. Examination of the tubes about four weeks later showed no visible growth, but spirochetes in moderate numbers were found in the depth of the medium in two tubes. This series was allowed to incubate further, and November 6 the two positive tubes were found to have visible growth in which a pure culture was found. Secondary cultures were made from these two tubes. Three weeks later, Nov. 27, 1915, a fine growth was seen in the second subcultures, which microscopically proved to be a pure culture in each case. Third subcultures were made from the richest of these two tubes. Jan. 3, 1916, subculture 3 showed a pure culture of actively motile organisms.

At present, over four months have elapsed from the time of the initial inoculation, and the organism has been carried through three successful subcultures, at the end of which time these are as actively motile and as rich as at first.

The question of a neurotropic strain with certain morphologic characteristics, different from other spirochete strains, has been suggested by the work of Noguchi, ${ }^{2}$ Nichols and Hough, ${ }^{3}$ and others. Clinical evidence points suggestively to the existence of such a strain. In the organisms which we have isolated from

1. Wile, U. J.: Experimental Syphilis in the Rabbit Produced by the Brain Substance of the Living Paretic, Jour. Exper. Med., 1916, xxiii, 199.

2. Noguchi, H.: München. med. Wchnschr., 1913, Ix, 2484.

3. Nichols, H. J., and Hough, W. H.: Positive Results Following the Inoculation of the Rabbit with Paretic Brain Substance, THe JourNAL A. M. A., July 12,1913, p. 120 . 
general paresis, there is no morphologic difference demonstrable. In the rabbit testis, numerous short thick forms with few spirals were found. In the cultures from this material, however, the predominating form was the typical fine spirochete with many convolutions, identical, in fact, with those seen in early cutaneous syphilids.

It is worthy of note, however, that although we had rich material to begin with, the cultures grew much more slowly and much less luxuriantly than do those cultivated from the early cutaneous or mucous membrane syphilids. On the other hand, it is to be noted that they are extremely viable. Examination at present of the original cultures, which have been disturbed by frequent examination and transplantation, still shows moderate numbers of organisms, actively motile and apparently as viable as when first seen.

\section{SANITATION AND THE CONTROL OF PELLAGRA}

CHARLES T. NESBITT, M.D.

Full-Time Health Officer, City of Wilmington and New Hanover County WILMINGTON, N. C.

That the incidence of pellagra is not decreased by improved sanitation and general disease prevention methods, and that it is materially increased by business depression and increased prices of food, is the conclusion that must be drawn from the experience obtained in this city during the past five years.

The following tables show the improvement in health conditions which have been secured since 1911 through improved water supply, excreta disposal by means of sanitary sewers, the general sanitation of the city, incineration of all waste and refuse, strict laboratory control of milk and water supply and the infections that are subject to laboratory control, market and food inspection, improved drainage, medical school inspection, and the various other methods used for human conservation in modern public health work.

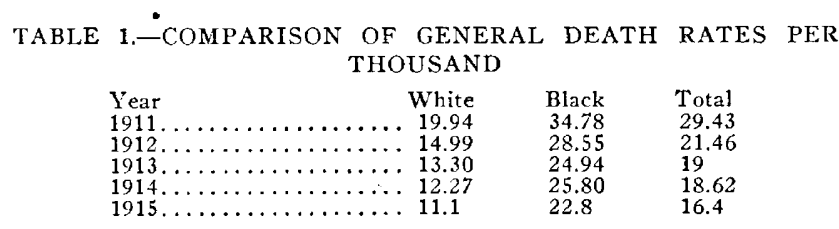

TARLE 2. - COMPARISON OF DEATH RATES UNDER FIVE YEARS PER HUNDRED THOUSAND; COMPUTED

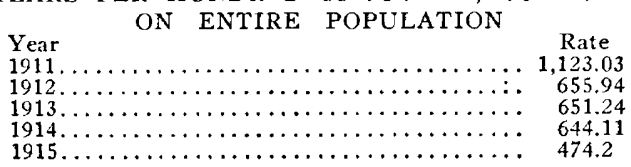

TABLE 3.-COMPARISON OF DEATH RATES FROM ENTEROCOLITIS PER HUNDRED THOUSAND

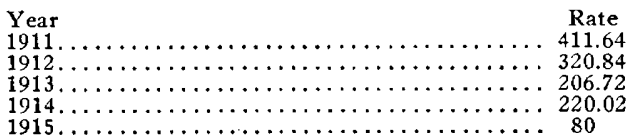

TABLE 4.-COMPARISON OF DEATH RATES FROM TYPHOID

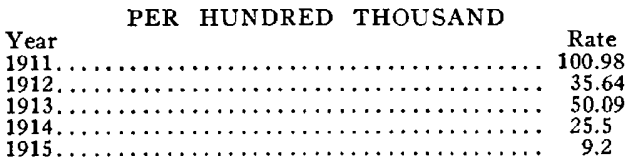

TABLE 5. - COMPARISON OF PERCENTAGE OF DEATHS FROM COMMUNICABLE DISEASES

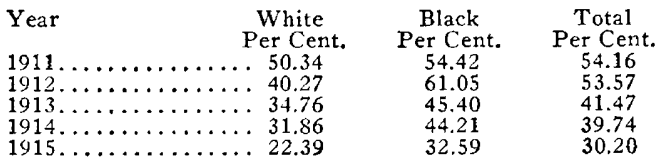

The percentages in Table 5 are computed to show the relation between the total number of deaths and the number of deaths from all known communicable diseases, including pellagra.

While this improvement was continuous, as shown in these tables, the death rate from pellagra shows a marked increase in 1915 over 1912, 1913 and 1914. In Table 6 is given a comparison of the death rates from this disease for the past five years.

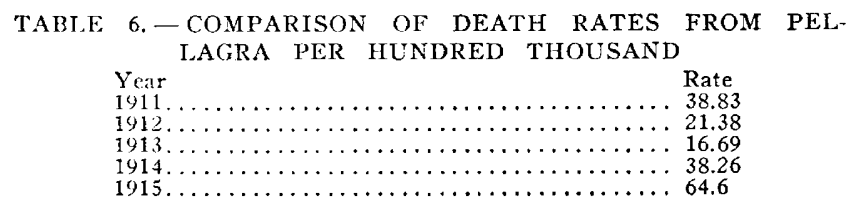

The years 1912 and 1913 were marked in this section by exceptional prosperity. The trucking industry and other industries of the county were very prosperous. The cotton market was active, and there was a marked increase in manufacturing and building activities. There was plenty of work for all, wages were good, and the prices of food were from 15 to 20 per cent. lower than they are now. With the outbreak of the war in the middle of 1914, there was an immediate depression, which has been more or less continuous though less marked at this time than up to June, 1915. The increase in the incidence of pellagra and the increase in the death rate of this disease follow this business depression very closely.

In the rural sections of New Hanover County a special intensive effort at sanitation began in July, 1914. The effort was concentrated on excreta disposal and water supply in order to control intestinal infections, which were especially prevalent. By the beginning of 1915 every rural home, black and white, in the county had been supplied with a privy at the owner's expense. At that time there were but twelve privies in the rural district which were not provided with receptacles and in which there was not a more or less successful effort at fly proofing. These conditions were maintained throughout 1915. Indeed, there was a marked improvement in this respect during 1915. In December, 1914, Prof. C. W. Stiles and Dr. L. L. Lumsden of the United States Public Health Service made a survey of the rural sections of this county with special reference to the methods of excreta disposal in use. A second survey was made in December, 1915, by Prof. C. W. Stiles of the United States Public Health Service and Dr. George M. Cooper, director of the Bureau of Rural Sanitation of the North Carolina State Board of Health. The last survey disclosed the fact that on the system of scoring used by the United States Public Health Service, the rural sanitary index in New Hanover County has been increased in a single year by 45 per cent. The rural population has been instructed in all disease prevention methods with the exception of pellagra, the means of preventing pellagra being only recently established. The incidence of this disease in the rural section as in the city has increased 